\title{
Beneficial Effect of Continuous Normobaric Hypoxia on Ventricular Dilatation in Rats With Post-Infarction Heart Failure
}

\author{
J. HRDLIČKA ${ }^{1,2}$, J. NECKÁŘ ${ }^{1}$, F. PAPOUŠEK ${ }^{1}$, J. VAŠINOVÁ ${ }^{1}$, P. ALÁNOVÁ ${ }^{1}$, \\ F. KOLÁ $\check{R}^{1}$
}

${ }^{1}$ Institute of Physiology, Czech Academy of Sciences, Prague, Czech Republic, ${ }^{2}$ Department of Physiology, Faculty of Science, Charles University in Prague, Prague, Czech Republic

Received January 26, 2016

Accepted March 18, 2016

On-line July 15, 2016

\begin{abstract}
Summary
Adaptation to continuous normobaric hypoxia $(\mathrm{CNH})$ protects the heart against ischemia/reperfusion injury but much less is known about its potential therapeutic effects. The aim of this study was to find out whether post-infarction exposure to $\mathrm{CNH}$ can attenuate the progression of heart failure. Ten-week-old male rats underwent myocardial infarction (MI) or sham operation. MI was induced by 60-min coronary artery occlusion. Seven days post-MI, the rats were randomly assigned to two groups: i) sedentary controls kept at room air and ii) rats exposed to $\mathrm{CNH}$ $\left(12 \% \mathrm{O}_{2}, 3\right.$ weeks). Echocardiographic examination of the left ventricle (LV) was performed 3 days before surgery and 7, 14 and 28 days post-MI. MI resulted in a gradual increase in LV end-diastolic diameter $\left(L V D_{d}\right)$ compared to sham-operated animals. Fractional shortening (FS) decreased from $42.8 \%$ before MI to $15.1 \%$ on day 28 post-MI. CNH significantly attenuated ventricular dilatation without affecting scar area and FS. Our data suggest that prolonged exposure to $\mathrm{CNH}$ has certain potential to attenuate the progression of unfavorable changes in ventricular geometry induced by MI in rats.
\end{abstract}

\section{Key words}

Chronic hypoxia $\bullet$ Heart failure $\bullet$ Myocardial infarction

\section{Corresponding author}

J. Hrdlička, Department of Developmental Cardiology, Institute of Physiology, Czech Academy of Sciences, Vídeňská 1083, 14220 Prague 4, Czech Republic. E-mail: jaroslav.hrdlicka@biomed.cas.cz
It has been well established that adaptation to chronic hypoxia confers long-lasting cardioprotection against various manifestations of injury caused by acute ischemia/reperfusion (I/R) insult. Increasing evidence has indicated that ischemia-resistant cardiac phenotype can be induced by both continuous hypoxia (Neckár et al. 2013, Chytilová et al. 2015) and certain regimens of intermittent hypoxia (reviewed in Kolář and Ošt'ádal 2004). However, much less attention has been paid to potential beneficial effects of chronic hypoxia in secondary prevention of chronic ischemic heart disease and post-infarction heart failure (HF). Del Pilar et al. (2006) demonstrated that intermittent hypobaric hypoxia (IHH) improved myocardial perfusion in patients with severe coronary heart disease. Exposure to repeated brief cycles of hypoxia and normoxia for 4 weeks improved cardiac contractile function in a transgenic mouse model of HF (Naghshin et al. 2012). Moreover, therapeutic action of $\mathrm{IHH}$ on post-infarcted rat hearts has been reported that manifested as a limitation of scar size and attenuation of both progressive myocardial remodeling and contractile dysfunction. These effects can be related to the increased angiogenesis and reduced apoptotic response in the border zone of infarction (Xu et al. 2011). It is unknown whether similar beneficial effects can be afforded by continuous hypoxia. Therefore, the aim of this study was to find out whether prolonged continuous exposure of rats to hypoxia ameliorates progression of post-infarction $\mathrm{HF}$.

Adult male Wistar rats (10-week-old, initial 
body weight 340-390 g, Anlab, Czech Republic) were housed in a controlled environment $\left(23^{\circ} \mathrm{C}\right.$; 12 :12-h lightdark cycle) and given water and a standard chow diet ad libitum. Animals were randomly assigned into 3 groups: i) sham-operated (Sham), ii) rats with myocardial infarction (MI) and iii) rats with MI exposed to continuous normobaric hypoxia $(\mathrm{CNH})(\mathrm{MI} / \mathrm{CNH})$. The study was conducted in accordance with the Guide for the Care and Use of Laboratory Animals (National Academy of Science, National Academy Press, Washington D.C.). The experimental protocols were approved by the Animal Care and Use Committee of the Institute of Physiology of the Czech Academy of Sciences.

Acute $\mathrm{I} / \mathrm{R}$ insult was performed in anesthetized (sodium pentobarbital, $60 \mathrm{mg} \mathrm{kg}^{-1}$ i.p.) open-chest rats ventilated with room air essentially as described previously (Neckář et al. 2002), except for coronary artery occlusion prolonged to $60 \mathrm{~min}$. Sham surgery was performed identically without occlusion. Then all spontaneously breathing animals recovering from anesthesia were housed in separate cages and received analgesis (Ibuprofen, $6 \mathrm{mg}$ /day p.o.) for another two days.
Since day 7 post-MI, the rats assigned to $\mathrm{CNH}$ were housed for 3 weeks in a hypoxic normobaric chamber $\left(\begin{array}{lll}12 \% & \mathrm{O}_{2}\end{array}\right)$ equipped with hypoxic generators (Everest Summit, Hypoxico Inc., NY, USA). A single 30 -min reoxygenation period occurred at day 14 for echocardiographic examination.

Echocardiography was performed 3 days before MI and 7, 14 and 28 days post-MI using GE Vingmed System Five (GE Vingmed Ultrasound, Horten, Norway) and FPA $10 \mathrm{MHz}$ probe (GE Vingmed Ultrasound, Horten, Norway). Animals were anesthetized with $2 \%$ isoflurane (Forane; Abbott Laboratories, Queenborough, UK) mixed with room air. Echocardiographic data were recorded and analysed in short and long axis of the heart and in 2D-mode and M-mode. Directly measured LV end-diastolic and end-systolic parameters included cavity diameter $\left(\mathrm{LVD}_{\mathrm{d}}\right.$ and $\left.\mathrm{LVD}_{\mathrm{s}}\right)$, anterior wall thickness $\left(\mathrm{AWT}_{\mathrm{d}}\right.$ and $\left.\mathrm{AWT}_{\mathrm{s}}\right)$ and posterior wall thickness $\left(\mathrm{PWT}_{\mathrm{d}}\right.$ and $\mathrm{PWT}_{\mathrm{s}}$ ). Based on the $\mathrm{LV}$ dimension, fractional shortening (FS) was derived as follows: FS $(\%)=\left[100 \times\left(\operatorname{LVD}_{\mathrm{d}}-\mathrm{LVD}_{\mathrm{s}}\right) /\left(\mathrm{LVD}_{\mathrm{d}}\right)\right]$. Values of heart rate $(\mathrm{HR})$ were averaged from at least 4 heart cycles.
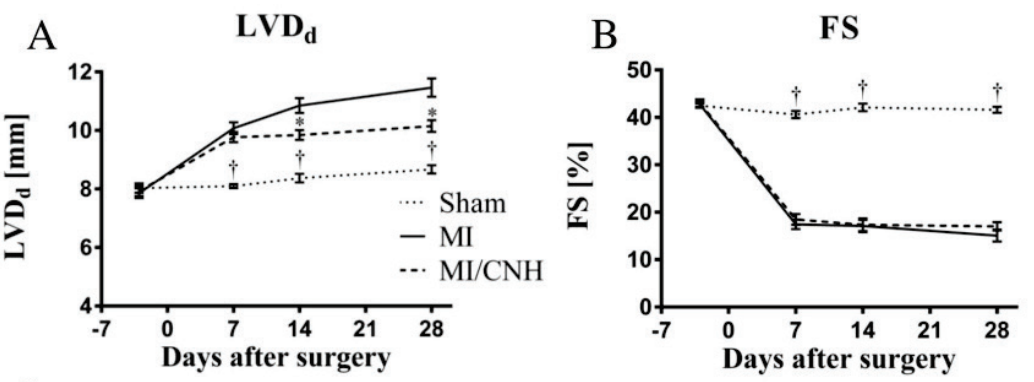

C
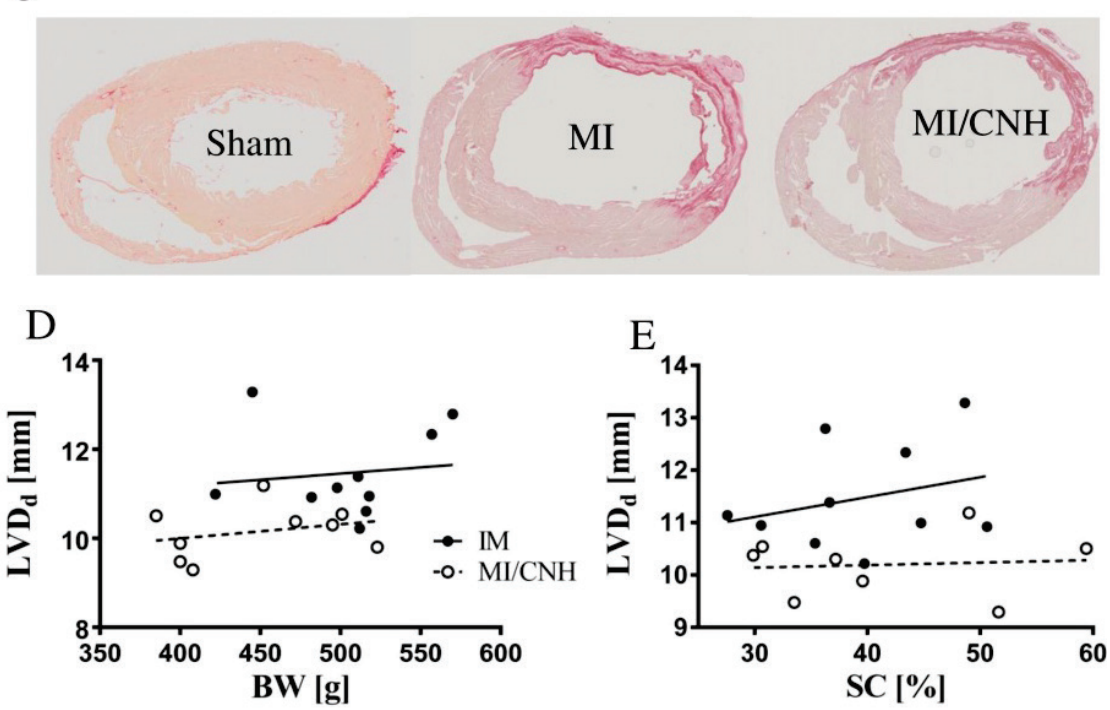

Fig. 1. Left ventricular (LV) echocardiographic parameters and histology of hearts from sham-operated rats (Sham), rats with myocardial infarction (MI) and rats with $\mathrm{MI}$ exposed to continuous normobaric hypoxia (MI/CNH). (A) LV end-diastolic diameter $\left(\operatorname{LVD}_{\mathrm{d}}\right)$, (B) Fractional shortening (FS), (C) Examples of transverse sections of hearts stained with Picrosirius Red for scar delineation at day 28 after surgery, (D) Relationship between body weight (BW) and $\mathrm{LVD}_{\mathrm{d}}$ at day 28 post-MI, (E) Relationship between scar circumference (SC) and $\mathrm{LVD}_{d}$ at day 28 post-MI. Values are means \pm SEM from 9-11 hearts in each group. * $\mathrm{P}<0.05$ $\mathrm{MI} / \mathrm{CNH}$ vs. MI, ${ }^{\dagger} \mathrm{P}<0.05$ Sham vs. IM and IM/CNH. 
After the last echocardiographic measurement, hearts were excised, washed with Tyrode's solution, perfusion-fixed and stored in $4 \%$ paraformaldehyde for 2 days at $4{ }^{\circ} \mathrm{C}$. Hearts were cut perpendicularly to the long axis at the largest circumference, embedded in paraffin, sectioned (9- $\mu \mathrm{m}$ slices) and stained with Picrosirius Red (Sigma-Aldrich, St. Louis, Missouri, USA). Slices were recorded with Olympus VS 110-S1 microscope (lens magnification 20×; Olympus, Hamburg, Germany) traced with computerized planimetry (OlyVIA 2.4, Olympus; NIS Elements 4.11, Laboratory Imaging, Prague, Czech Republic) and the relative scar area (scar area/LV area) and scar circumference (scar midwall length/LV midwall circumference) were determined (Pfeffer et al. 1979) and expressed in percentage.

Data are presented as means \pm SEM Statistical evaluations were done using one-way ANOVA with Newman-Keuls post-hoc test using GraphPad Prism 6 (GraphPad Software, San Diego, CA, USA). Differences were considered significant when $\mathrm{P}<0.05$.

$\mathrm{I} / \mathrm{R}$ insult led to $56 \%$ mortality within $48 \mathrm{~h}$ postMI compared to $100 \%$ survival in sham-operated group.
Sustained ventricular fibrillation was the main cause of death. Mortality was comparable to earlier reports using similar models of large MI (Pfeffer et al. 1985, Bech et al. 1990) and did not change since day 2 post-MI. Contraction of LV anterior wall ceased after MI, $\mathrm{AWT}_{\mathrm{d}}$ and $\mathrm{AWT}_{\mathrm{s}}$ decreased by $17.7 \%$ and $43.1 \%$, respectively, compared to Sham group at day 7 and did not change significantly till day 28; the exposure to $\mathrm{CNH}$ had no effect. No differences in PWT were observed among the groups, except for the $16.1 \%$ increase in $\mathrm{PWT}_{\mathrm{d}}$ in MI/CNH compared to Sham group (Table 1). As shown in Fig. $1 \mathrm{~A}, \mathrm{LVD}_{\mathrm{d}}$ progressively increased after $\mathrm{MI}$ and $\mathrm{CNH}$ significantly attenuated this effect: between days 7 and $28, \mathrm{LVD}_{\mathrm{d}}$ grew by $13.7 \%$ and $3.9 \%$ in $\mathrm{MI}$ and $\mathrm{MI} / \mathrm{CNH}$ groups, respectively. Corresponding changes occurred in $\mathrm{LVD}_{\mathrm{s}}$ (Table 1). FS dropped markedly after MI but no beneficial effect of $\mathrm{CNH}$ was observed (Fig. 1B). Histological analysis did not reveal any effect of $\mathrm{CNH}$ on scar area $(21.0 \pm 1.1 \%$ and $19.8 \pm 2.0 \%$ in MI and $\mathrm{MI} / \mathrm{CNH}$, respectively) and scar circumference $(39.4 \pm 2.4 \%$ and $39.4 \pm 3.9 \%$ in $\mathrm{MI}$ and $\mathrm{MI} / \mathrm{CNH}$, respectively) (Fig. 1C).

Table 1. Body weight (BW) and left ventricular (LV) echocardiographic parameters of hearts from sham-operated rats (Sham), rats with myocardial infarction (MI) and rats with MI exposed to continuous normobaric hypoxia (MI/CNH).

\begin{tabular}{|c|c|c|c|c|c|c|c|c|}
\hline $\begin{array}{l}\text { Days after } \\
\text { surgery }\end{array}$ & Group & $\begin{array}{l}\text { BW } \\
(\mathrm{g})\end{array}$ & $\begin{array}{c}\text { HR } \\
(\mathrm{bpm})\end{array}$ & $\begin{array}{l}\mathbf{L V D} D_{\mathrm{s}} \\
(\mathrm{mm})\end{array}$ & $\begin{array}{c}\mathbf{A W T}_{\mathrm{d}} \\
(\mathrm{mm})\end{array}$ & $\begin{array}{l}\mathbf{A W T}_{\mathrm{s}} \\
(\mathrm{mm})\end{array}$ & $\begin{array}{l}\mathbf{P W T}_{\mathbf{d}} \\
(\mathbf{m m})\end{array}$ & $\begin{array}{l}\mathbf{P W T}_{\mathrm{s}} \\
(\mathbf{m m})\end{array}$ \\
\hline \multirow{3}{*}{-3} & Sham & $365 \pm 19$ & $377 \pm 8$ & $4.65 \pm 0.09$ & $2.14 \pm 0.09$ & $3.28 \pm 0.08$ & $1.82 \pm 0.03$ & $2.86 \pm 0.05$ \\
\hline & MI & $379 \pm 22$ & $382 \pm 14$ & $4.52 \pm 0.13$ & $2.13 \pm 0.06$ & $3.30 \pm 0.08$ & $1.95 \pm 0.06$ & $3.01 \pm 0.08$ \\
\hline & $\mathrm{MI} / \mathrm{CNH}$ & $341 \pm 25$ & $375 \pm 8$ & $4.53 \pm 0.12$ & $2.04 \pm 0.07$ & $3.26 \pm 0.10$ & $1.86 \pm 0.07$ & $2.67 \pm 0.09$ \\
\hline \multirow{3}{*}{7} & Sham & $425 \pm 12$ & $387 \pm 7$ & $4.83 \pm 0.06^{\dagger}$ & $2.26 \pm 0.06^{\dagger}$ & $3.34 \pm 0.09^{\dagger}$ & $1.92 \pm 0.04$ & $2.93 \pm 0.06$ \\
\hline & MI & $409 \pm 17$ & $378 \pm 8$ & $8.34 \pm 0.25$ & $1.86 \pm 0.07$ & $1.90 \pm 0.07$ & $1.95 \pm 0.09$ & $2.92 \pm 0.09$ \\
\hline & $\mathrm{MI} / \mathrm{CNH}$ & $382 \pm 20$ & $362 \pm 6$ & $7.97 \pm 0.18$ & $1.91 \pm 0.11$ & $1.96 \pm 0.12$ & $2.11 \pm 0.06$ & $2.96 \pm 0.12$ \\
\hline \multirow{3}{*}{14} & Sham & $465 \pm 13^{*}$ & $377 \pm 7$ & $4.87 \pm 0.14^{\dagger}$ & $2.33 \pm 0.07^{\dagger}$ & $3.56 \pm 0.08^{\dagger}$ & $2.04 \pm 0.09$ & $3.15 \pm 0.05$ \\
\hline & MI & $446 \pm 16$ & $390 \pm 8$ & $9.02 \pm 0.34$ & $1.81 \pm 0.06$ & $1.77 \pm 0.05$ & $2.00 \pm 0.04$ & $3.05 \pm 0.07$ \\
\hline & $\mathrm{MI} / \mathrm{CNH}$ & $400 \pm 22$ & $365 \pm 9$ & $8.13 \pm 0.19 *$ & $1.84 \pm 0.06$ & $1.84 \pm 0.06$ & $2.13 \pm 0.08$ & $3.12 \pm 0.14$ \\
\hline \multirow{3}{*}{28} & Sham & $527 \pm 12^{\ddagger}$ & $367 \pm 5$ & $5.09 \pm 0.07^{\dagger}$ & $2.25 \pm 0.07^{\dagger}$ & $3.54 \pm 0.09^{\dagger}$ & $1.99 \pm 0.06^{\ddagger}$ & $3.17 \pm 0.07$ \\
\hline & MI & $503 \pm 14$ & $376 \pm 7$ & $9.77 \pm 0.39$ & $1.81 \pm 0.03$ & $1.83 \pm 0.04$ & $2.12 \pm 0.06$ & $3.11 \pm 0.06$ \\
\hline & $\mathrm{MI} / \mathrm{CNH}$ & $448 \pm 17 *$ & $341 \pm 15^{*}$ & $8.43 \pm 0.22 *$ & $1.84 \pm 0.06$ & $1.89 \pm 0.07$ & $2.31 \pm 0.08$ & $3.24 \pm 0.08$ \\
\hline
\end{tabular}

Values are means \pm SEM from 9-11 rats in each group. HR, heart rate; LVD $_{s}$, end-systolic LV diameter; AWT , end-diastolic anterior wall thickness; $\mathrm{AWT}_{\mathrm{s}}$, end-systolic anterior wall thickness; $\mathrm{PWT}_{\mathrm{d}}$, end-diastolic posterior wall thickness; $\mathrm{PWT}$, end-systolic posterior wall thickness. * $\mathrm{P}<0.05 \mathrm{MI} / \mathrm{CNH}$ vs. $\mathrm{MI},{ }^{\dagger} \mathrm{P}<0.05$ Sham vs. $\mathrm{MI}$ and $\mathrm{MI} / \mathrm{CNH},{ }^{\ddagger} \mathrm{P}<0.05$ Sham vs. $\mathrm{MI} / \mathrm{CNH}$.

As adaptation to $\mathrm{CNH}$ resulted in lower body weight compared to MI group (Table 1), it can be argued that body growth retardation was responsible for the attenuation of MI-induced LV dilatation (Litwin et al.
1994). However, the relationship between body weight and $\mathrm{LVD}_{\mathrm{d}}$ (Fig. 1D) clearly shows that it cannot fully explain the beneficial effect of $\mathrm{CNH}$. Similar attenuation of $\mathrm{LV}$ dilatation has been observed in infarcted rats 
exposed to chronic IHH which did not affect body weight (Xu et al. 2011). It also should be noted that the CNHinduced $\mathrm{LVD}_{\mathrm{d}}$ lowering compared to MI group was independent of the proportion of scar tissue (Fig. 1E). In contrast to the study of Xu et al. (2011), we did not observe any improvement of FS in infarcted rats adapted to $\mathrm{CNH}$. The reason for this discordance is unknown but differences between models and protocols of IHH and $\mathrm{CNH}$ can play a role. In addition, it cannot be excluded that the large extent of MI injury in our study already exceeded the limits of potential effective amelioration of systolic function by chronic hypoxia.

In conclusion, the prolonged exposure of rats to $\mathrm{CNH}$ has certain therapeutic potential against the unfavorable changes in ventricular geometry induced by severe MI. Further studies are needed to optimize $\mathrm{CNH}$ protocol in order to alleviate the progression of MI-induced heart failure.

\section{Conflict of Interest}

There is no conflict of interest.

\section{Acknowledgements}

This study was supported by Grant Agency of the Charles University in Prague (project GA UK 798813 to J. H.), Ministry of Health of the Czech Republic (grant 15-27735A to J. N.) and Czech Science Foundation (grant 303/12/1162 to F. K.).

\section{References}

BECH OM, SØRENSEN JD, JENSEN MK, DIAMANT B, STEINESS E: Effects of long-term coenzyme Q10 and captopril treatment on survival and functional capacity in rats with experimentally induced heart infarction. J Pharmacol Exp Ther 255: 346-350, 1990.

CHYTILOVÁ A, BORCHERT GH, MANDÍKOVÁ-ALÁNOVÁ P, HLAVÁČKOVÁ M, KOPKAN L, KHAN MA, IMIG JD, KOLÁ̌̌ F, NECKÁŘ J: Tumour necrosis factor- $\alpha$ contributes to improved cardiac ischaemic tolerance in rats adapted to chronic continuous hypoxia. Acta Physiol (Oxf) 214: 97-108, 2015.

KOLÁŘ F, OŠŤÁDAL B: Molecular mechanisms of cardiac protection by adaptation to chronic hypoxia. Physiol Res 53 (Suppl 1): S3-S13, 2004.

LITWIN SE, KATZ SE, MORGAN JP, DOUGLAS PS: Serial echocardiographic assessment of left ventricular geometry and function after large myocardial infarction in the rat. Circulation 89: 345-354, 1994.

NAGHSHIN J, RODRIGUEZ RH, DAVIS EM, ROMANO LC, MCGAFFIN KR, O'DONNELL CP: Chronic intermittent hypoxia exposure improves left ventricular contractility in transgenic mice with heart failure. J Appl Physiol 113: 791-798, 2012.

NECKÁŘ J, PAPOUŠEK F, NOVÁKOVÁ O, OŠŤÁDAL B, KOLÁŘ F: Cardioprotective effects of chronic hypoxia and ischaemic preconditioning are not additive. Basic Res Cardiol 97: 161-167, 2002.

NECKÁR̆ J, BORCHERT GH, HLOUŠKOVÁ P, MÍČOVÁ P, NOVÁKOVÁ O, NOVÁK F, HROCH M, PAPOUŠEK F, OŠŤÁDAL B, KOLÁŘ F: Brief daily episode of normoxia inhibits cardioprotection conferred by chronic continuous hypoxia. Role of oxidative stress and BKCa channels. Curr Pharm Des 19: 6880-6889, 2013.

PFEFFER MA, PFEFFER JM, FISHBEIN MC, FLETCHER PJ, SPADARO J, KLONER RA, BRAUNWALD E: Myocardial infarct size and ventricular function in rats. Circ Res 44: 503-512, 1979.

PFEFFER MA, PFEFFER JM, STEINBERG C, FINN P: Survival after an experimental myocardial infarction: beneficial effects of long-term therapy with captopril. Circulation 72: 406-412, 1985.

DEL PILAR VALLE M, GARCÍA-GODOS $\mathrm{F}$, WOOLCOTT OO, MARTICORENA JM, RODRÍGUEZ V, GUTIÉRREZ I, FERNÁNDEZ-DÁVILA L, CONTRERAS A, VALDIVIA L, ROBLES J, MARTICORENA EA: Improvement of myocardial perfusion in coronary patients after intermittent hypobaric hypoxia. $J \mathrm{Nucl}$ Cardiol 13: 69-74, 2006.

XU WQ, YU Z, XIE Y, HUANG GQ, SHU XH, ZHU Y, ZHOU ZN, YANG HT: Therapeutic effect of intermittent hypobaric hypoxia on myocardial infarction in rats. Basic Res Cardiol 106: 329-342, 2011. 